\title{
Child Acute Lower Respiratory Tract Infection in Pediatrics Intensive Care Unit at University Hospital of Brazzaville (Congo)
}

\author{
Engoba Moyen"1,2, Judicaël Kambourou',2, Annie Rachelle Okoko',2, \\ Lori Bertrand Nguelongo ${ }^{1,2}$, Verlem Bomelefa-Bomel ${ }^{1,2}$, \\ Kadidja Grace Nkounkou1,2, Georges Moyen ${ }^{1,2}$, Jean-Louis Nkoua1 \\ ${ }^{1}$ Faculty of Health Sciences, Marien Ngouabi University of Brazzaville, Brazzaville, Congo \\ ${ }^{2}$ Pediatric Intensive Cares Unit, University Hospital of Brazzaville, Brazzaville, Congo \\ Email: engoba_m@yahoo.fr
}

How to cite this paper: Moyen, E., Kambourou, J., Okoko, A.R., Nguelongo, L.B., Bomelefa-Bomel, V., Nkounkou, K.G., Moyen, G. and Nkoua, J.-L. (2018) Child Acute Lower Respiratory Tract Infection in Pediatrics Intensive Care Unit at University Hospital of Brazzaville (Congo). Open Journal of Pediatrics, 8, 32-41.

https://doi.org/10.4236/ojped.2018.81005

Received: December 27, 2017

Accepted: March 5, 2018

Published: March 8, 2018

Copyright $\odot 2018$ by authors and Scientific Research Publishing Inc. This work is licensed under the Creative Commons Attribution International License (CC BY 4.0).

http://creativecommons.org/licenses/by/4.0/

\begin{abstract}
In order to contribute to reduction of morbidity and mortality due to low acute respiratory infections in pediatrics, the objective of this study was to determine the epidemiological profile and to identify the factors favoring and those associated with the risk of deceased. We reviewed the cases of children aged between 1 and 59 months hospitalized between January and December 2015 in the pediatric intensive care unit of the CHU of Brazzaville and retained those whose diagnosis of discharge was an ALRI. The study variables were: epidemiological, clinical, paraclinic, diagnostic, therapeutic and evolutionary. For 2012 hospitalized children, 400 (19.8\%) were hospitalized for an ALRI. There were 235 boys (58.8\%) and 165 girls (41.2\%) of average age. Infants aged 1 to 11 months were the most affected $n=260$ (65\%). They were insufficiently immunized with haemophilus influenza $B$ and pneumococcus $n$ $=378$ (94.5\%); Fully immunized $\mathrm{n}=20$ (5\%), the average delay for consultation after the first symptom was $5.03 \pm 3.86$ days; Denutrition was rated $\mathrm{n}=$ $180(45 \%)$, positive retroviral serology $\mathrm{n}=19$ cases $(4.8 \%)$. The main nosological varieties were: bronchiolitis $\mathrm{n}=223(55.7 \%)$, pneumonia $\mathrm{n}=145$ (36.2\%). One death was rated $n=65$ (16.3\%). The mortality determinants were: prematurity, vaccination status and HIV/AIDS infection. The frequency and severity of ALRIs necessitates a strengthened program of integrated management of childhood illnesses, and public health actions targeting the factors that promote and contribute to the risk of death.
\end{abstract}

\section{Keywords}

Acute Respiratory Infections, Child, Brazzaville, Bronchiolitis 


\section{Introduction}

Acute lower respiratory tract infections (ALRIs) are common and frequent group of diseases caused by a wide range of pathogens (viruses, bacteria, fungi or parasites) in which the possible anatomic site(s) extend from the trachea to the alveoli. They are considered as real public health problem in the world and are the most common reason for pediatric consultation and antibiotic prescriptions [1] [2] [3] [4] [5].

High incidence rates of ALRIs are observed both developed and developing countries [2] [5] [6] [7] [8]. Furthermore, they are globally the leading cause of infectious disease-related deaths, estimated mortality averages four millions deaths per year, mainly due to pneumonia [2]. In Europe, they are the leading cause of hospitalization [3]. In African countries, they are the leading cause of consultation in the health services and the third leading cause of death after malaria and diarrheal diseases [5] [6] [7].

In Congo, in 2003, ALRIs were the second leading cause of pediatric hospitalization with a frequency of $22.4 \%$ after severe malaria. Pneumococcus and haemophilus were the main causative agents [6]. In addition, in 2009, pneumococcal and haemophilus B vaccines were added in the Expanded Program on Immunization. In order to contribute to the reduction of the morbidity and the mortality relative to the ALRIs of children in Brazzaville, this study set itself the objective of determining their epidemiological, clinical and evolutionary profiles and to identify the favoring factors and those associated with the risk of death.

\section{Patients and Method}

\section{Methods}

This retrospective descriptive and analytical study was conducted in 12 months, between January and December 2015, at the Brazzaville Hospital and University Hospital Level Three Public Hospital, in the pediatric intensive care unit, the only service that supports vital distress of the child. We reviewed all records of children aged one to 59 months and selected those with an exit diagnosis that included the ALRI item. Children with cardipathies were excluded. The term ALRI included: acute broncho-pneumonia for bacterial infections, bronchiolitis for viral infections, pneumonia and pleuro-pneumonia. Since some of these ALRIs are vaccine-preventable, we evaluated the immunization status of the patients. Children with complete immunization coverage received at least three doses of pneumococcal and anti Haemophilus influenzae vaccine and two doses of measles vaccine. On the other hand, those with incomplete immunization coverage received less than three doses of pneumococcal vaccine and Haemophilus influenzae and one dose of measles vaccine. Unvaccinated children were those who had received no dose. The other variables studied were socio-demographic, clinical and para-clinical characteristics, treatment administered, and evolution. 
The statistical analysis was done using the SPSS software version 20. Quantitative variables were expressed as mean \pm standard deviation and qualitative variables in number and percentage. The Pearson Khi2 test and Fisher's exact test allowed the comparison of the variables. The significance level was set to $p$ less than or equal to $0.05(p<0.05)$.

\section{Results}

\subsection{Epidemiological Aspects}

During the study period, 2012 children were hospitalized, of whom 700 had respiratory disease including $400(19.9 \%)$ with ALRIs. There were 235 boys (58.8\%) and 165 girls (41.2\%), a sex ratio H/F of 1.4.

ALRI was the second leading cause of hospitalization after malaria ( $\mathrm{n}=800$ or $39.8 \%$ ). Children were aged on average of $13.3 \pm 14.6$ months (range $=1$ to 59 months). In 260 (65\%) cases, they were 1 and 11 months old, 98 (24.5\%) were 12 and 35 months old, and $42(10.5 \%)$ were 36 and 59 months old. They came from home in 331 cases (82.7\%) and from a health center in 69 (17.3\%).

They were hospitalized during the rainy seasons in 250 cases $(62.5 \%)$, precisely during the short rainy season from October to December in 176 cases (43.2\%), and the main rainy season from April to June ( $n=74 \%$ or $18.5 \%$ ). In 150 cases (37.5\%), hospitalization took place during the dry season, especially in the main dry season (July-September) in 94 cases (23.5\%) and in the short dry season (January-March). in 56 cases (14.0\%).

\subsection{Personal and Family History}

Mothers were aged on average $32.6 \pm 5.9$ years (range: 17 to 50 years). In 120 cases (30.0\%), mothers were out of school. Of the 280 school-aged mothers, 42 (15.0\%) had a higher level of education, 138 (49.3\%) had a secondary level, and $100(35.7 \%)$ a primary level. These mothers were civil servants in 32 cases (8\%), workers in 226 cases (56.5\%), informal sector workers in 92 cases (23\%), and jobless in 50 cases (12.5\%). On the other hand, fathers averaged $38.6 \pm 6.9$ years with extremes of 19 and 60 years, and they had higher level of education in 45 cases $(11.2 \%)$, secondary in 230 cases $(57.5 \%)$, primary in 100 cases $(25.0 \%)$ and 25 (6.3\%) were out of school. They were civil servants in 50 (12.5\%), workers in 218 (54.5\%), informal sector workers in 73 (18.3\%), senior managers in $2(0.5 \%)$, and jobless in 57 (14.2\%).

Children were born premature in 12 cases (3\%), had had an episode of bronchiolitis in 36 cases (9\%), and pneumonia in 10 (2.5\%). The immunization coverage status against Haemophilus Influenzae B and Pneumococcus was incomplete in 378 cases (94.5\%), complete in $20(5.0 \%)$ while two children $(0.5 \%)$ had not been vaccinated. The ALRIs occurred after measles in $2(0.5 \%)$ cases, and after accidental ingestion of oil in $10(2.5 \%)$ cases. No history of asthma, atopy, and passive smoking were found. Before hospitalization, treatment had been administered to 378 children (94.5\%), by parents to 320 children (84.6\%) with 
antibiotics being obtained over-the-counter, and by a health worker in 58 children (15.4\%). It consisted of an antibiotherapy in 193 cases (51.0\%), symptomatic treatment in 183 cases (48.5\%) and anti-malarial/ antibiotic combination (0.5\%).

\subsection{Clinical and Para-Clinical Signs}

The mean time to symptom appearance and admission was 5.0 days \pm 3.8 with extremes of 1 and 30 days.

The main functional clinical signs found were, polypnea in all cases, intercostal retraction $(\mathrm{n}=380: 95 \%)$ and xiphoid retraction $(\mathrm{n}=100: 25 \%)$, and on physical examination. crackles $(\mathrm{n}=200: 50 \%)$, sibilant rales $(\mathrm{n}=189: 47.2 \%)$, and dullness $(\mathrm{n}=4: 3.5 \%)$ (Table 1$)$.

There was respiratory distress in 382 cases (95.5\%), hypodynamia in 12 (3\%), and seizures in 6 cases (1.5\%). A nutritional disorder existed in 180 children or $45.0 \%$, emaciation ( $\mathrm{n}=110 \%$ or $61.1 \%)$, and severe emaciation in $70(38.9 \%)$.

In 350 cases $(87.5 \%)$, parenchymal lesions were seen on the chest $\mathrm{x}$-ray. they were either bilateral in 180 (51.4\%), or lateral uni in 170 (48.6\%), associated with pleural opacity in 14 children (7.14\%). These images consisted of thoracic distention in 189 cases (54.0\%), alveolar opacity in 57 (16.3\%), alveolar-interstitial opacity in 50 in (14.3\%), interstitial opacity in 40 (11.4\%), and pleural opacity in 14 cases $(4.0 \%)$.

A pulmonary echography was performed in 14 children (7.14\%) and identified encysted pleurisy and lung abscess in two cases (0.5\%) each. Bacteriological examination of the pleural fluid was requested in $14(\mathrm{n}=7.14 \%)$ and Pneumococcus isolated in 6 cases (1.5\%), and Staphylococcus in one case $(0.2 \%)$. HIV serology in 150 children was positive in 19 children (12.7\%), of which nine (2.2\%) had bronchopneumonia, five (1.25\%) pneumonia, and five $(1.25 \%)$ pleuropneumonia $(0.3 \%)$. Virological examinations were not performed in all cases.

\subsection{Types of ALRI and Associated Pathologies}

It was bronchiolitis in 226 (56.5\%), bronchopneumonia in 145 cases (36.2\%), pneumonia in $21(5.3 \%)$, and pleuropneumonia in $8(2.0 \%)$.

The ALRI was associated with biologically confirmed malaria in 111 children (61.6\%), and acute gastroenteritis in 76 (42.2\%).

Table 1. Major isolated and/or associated signs in 400 cases of acute respiratory infection.

\begin{tabular}{ccc}
\hline & $\mathrm{N}$ & $\%$ \\
\hline Polypnea & 400 & 100 \\
Intercostal printing & 380 & 95 \\
Xiphoid funnel & 100 & 25 \\
Matiety & 14 & 3.5 \\
Crackling rales & 200 & 50 \\
Subcrackling rales & 200 & 50 \\
Sibilants & 189 & 47.2 \\
\hline
\end{tabular}


The occurrence of bronchiolitis and bronchopneumonia disease was closely related to the season.

\subsection{Treatment}

Probabilistic antibiotic therapy was prescribed to 245 children (61.3\%), a third-generation cephalosporin $\mathrm{n}=116(46.4 \%)$, amoxicillin $\mathrm{n}=92(36.8 \%)$, an amoxicillin-clavulanic acid combination $\mathrm{n}=14(5.7 \%)$, cotrimoxazole $\mathrm{n}=18$ (7.3\%), an aminoglycoside $\mathrm{n}=10(4 \%)$, a macrolide $\mathrm{n}=8(3.2 \%)$, lincomycin $\mathrm{n}$ $=6(1.5 \%)$, pristinamycin and vancomycin in one case each $(0.4 \%)$. The aminoglycoside, lincomycin, pristinamycin and vancomycin have in all cases been prescribed in combination. The average duration of antibiotherapy was five days (range 2 - 14 days) for bronchopneumonia; extremes of 5 and 14 days for pleuropneumonia; extremes of 3 and 14 days for pneumonia, extremes of 1 and 14 days for bronchiolitis.

A corticoid treatment was administered in 30 children (7.5\%), 18 (60\%) for bronchiolitis, six (1.5\%) for bronchopneumonia, six (1.5\%) for pneumonia, and four (1\%) pleuropneumonia. Respiratory physiotherapy was done in 100 children $(25.0 \%)$ hospitalized for bronchiolitis.

\subsection{Evolution}

The average duration of hospitalization was $4 \pm 2.1$ days ( 1 and 14 days). Healing was obtained in 325 cases (83.7\%) of which 263 in (65.8\%) without complications. We observed non-lethal complications in 72 cases (18\%): severe sepsis in 69 cases (98.6\%), pleurisy in 2 cases (0.5\%), and lung abscess in 1 (1.4\%).

One death was noted in 65 cases, a lethality of $16.3 \%$, and a mortality of 3.23 . The average age of children who died was $13.3 \pm \mathrm{x}$, y months (range 1 to 60 months), including 25 infants (38.5\%) less than 12 months of age.

Nosologically, these 65 children had bronchopneumonia ( $\mathrm{n}=46$ equivalent of $31.7 \%$ lethality), pneumonia $(\mathrm{n}=16 \%$ or $76.2 \%)$, and pleuropneumonia $(\mathrm{n}=3)$. lethality of $37.5 \%)$.

\subsection{Determinants of ALRI Occurrence and Lethal Outcome Are Shown in Table 2}

The determinants of death identified were: HIV seropositivity and severe emaciation, excluding other factors: age, gender, season of onset, and other nutritional status.

\section{Discussion}

\subsection{Analysis of Methods}

The aim of this study, which focuses on the ALRI of children under five years of age, was to contribute to the reduction of morbidity and mortality related to ALRIss and specifically to determine their clinical and evolutionary epidemiological profile as well as the factors associated with death (Table 3). 
Table 2. Respiratory infections and seasons.

\begin{tabular}{|c|c|c|c|c|c|c|}
\hline \multirow[t]{3}{*}{ Type of infections } & \multicolumn{4}{|c|}{ Season } & \multirow[t]{3}{*}{ OR (IC 95\%) } & \multirow[t]{3}{*}{$p$} \\
\hline & \multicolumn{2}{|c|}{ Rainy } & \multicolumn{2}{|l|}{ Dry } & & \\
\hline & $\mathrm{N}$ & $\%$ & $\mathrm{~N}$ & $\%$ & & \\
\hline Bronchiolitis & 129 & 49.4 & 97 & 70.8 & $0.39(0.26-0.62)$ & 0.000032 \\
\hline Broncho-pneumopathy & 116 & 44.1 & 29 & 21.2 & $2.84(1.47-2.96)$ & 0.00001 \\
\hline Pneumonias & 12 & 4.6 & 9 & 6.6 & $0.78(0.48-1.29)$ & 0.333 \\
\hline Pleuro-pneumopathy & 6 & 2.3 & 2 & 1.5 & $1.56(0.32-7.64)$ & 0.721 \\
\hline Total & 263 & 100 & 137 & 100 & & \\
\hline
\end{tabular}

Table 3. Factors associated with death.

\begin{tabular}{ccccc}
\hline Factors & Death & OR (IC 95\%) & $p$ \\
\hline Age $<12$ month & N & $\%$ & & \\
Male sex & 45 & 69.2 & $1.2(0.70-2.20)$ & 0.43 \\
Rainy season & 33 & 50.8 & $0.67(0.39-1.15)$ & 0.154 \\
HIV + & 44 & 67.7 & $1.10(0.62-1.95)$ & 0.71 \\
severe emaciation & 9 & 13.8 & $5.20(2.03-13.40)$ & $<0.001$ \\
\hline
\end{tabular}

The frequency of ALRIs is $13.9 \%$, they are observed incompletely vaccinated children $94.5 \%$. Bronchiolitis $56.5 \%$, bronchopneumonia $36.2 \%$ and pneumonia $5.5 \%$ are the most prevalent. One death was noted in $16.3 \%$ and the determinants of death were HIV/AIDS seropositivity and severe emaciation. The still high mortality and lethality that we have observed, therefore, indicates the seriousness of the situation and the urgency for corrective measures for forms of low respiratory infections that can be prevented by vaccination.

This study has some limitations. The first relates to the hospitable and mono-centric character of the study.

Although bieng performed in a pediatric intensive care unit, in which patients recruitment is selective, ALRIs cases treated as ambulatory patiens were not included. On the other hand, the mono-centric character may suggest a recruitment bias. The second limit is related to the retrospective nature of the study, which is a source of selection bias and lost to follow-up. But because of the size of the sample, and especially the study framework (University Hospital of Brazzaville, in the only Intensive care unit department available in the city with staff and adapted equipment), the results of this study can be extrapolated to the entire child population of the city Brazzaville.

\subsection{Frequency, Age, and Influence of the Seasons}

Children's ALRIs are an important part of pediatric infectious pathology and account for $10 \%$ of general pediatric hospitalizations [7]. In our department, 
they represented $22.4 \%$ of the patients hospitalized in this work, $20 \%$ in a previous work [6]. Elsewhere in Africa, frequencies reported in various countries [5] [7] [8] [9] [10] were still higher than in the industrialized countries but proportionally lower than in our work. But this work has taken place in general pediatric departments: the way patients are recruited from our study frame can explain this difference. It is known [11] that the major problem related to acute respiratory infection mainly affects children under 5 and is located in developing countries because of their age pyramid, the climatic as reported in this work, habitat hygiene, promiscuity, low birth weight, malnutrition and deficiencies, failures of health systems. Also, prematurity has been identified as a favoring factor of ALRIs, undoubtedly due to pulmonary immaturity [3] [12] [13].

Previously we observed an average age of onset of 13.4 months versus 29 months in the same department [6]. In Togo [7], 66.7\% of children admitted for Lower respiratory tract infection were less than 2 years old and $88.3 \%$ under 5 years of age, while in Thailand [3], $72.1 \%$ of children in children with less than a year. The male predominance usually reported [3] [5] [6] [7] has been confirmed in our work. Similarly, the link between the occurrence of ALRIs and the seasons was found in our study with a peak frequency during the long rainy season. This peak of frequency was noted during the harmattan season and the great rainy season in Togo [Bakonde], and in Thailand [3]. Similarly, in Europe [14] [15] [16], bronchiolites were readily observed in the winter, and in Argentina [17] the peak frequency was observed in the dry season.

\subsection{Diagnosis of ALRIs of the Child}

The diagnosis is generally easy [18], especially since the disease is common in sub-Saharan Africa [9] [19], children are seen late, on average five days after the onset of symptoms in our work. This is one of the reasons for the frequency of severe forms, justifying hospitalization or even hospitalization in a pediatric intensive care unit. Moroever, the choice of a site for the care of children presenting with an ALRI is based on their severity. No score has been validated to assess the severity of the child's ALRI. It is appreciated by the clinical evaluation of the practitioner [20] by the presence of signs such as the refusal to drink and a temperature higher than 38.5 in the infant, the presence of bronchial rales, and a respiratory rate higher than 60 per minute in the great child. The detection of hypoxia by clinical examination or by the measurement of pulse oximetry or oxygen saturation is also an important criterion.

The ALRI is located [21] in the bronchi (bronchitis and bronchiolitis), generally of viral origin or lung parenchyma and/or the pleura and then the most common cause of germs are Streptococcus pneumoniae, Haemophilus inflenzae, Staphylococcus aureus. In our experience, broncho-pneumopathies ( $\mathrm{n}$ $=145)$ and pneumonias $(\mathrm{n}=21)$ were the most common nosological forms behind bronchiolitis $(\mathrm{n}=226)$.

But since the identification of the germ is linked to the diagnostic methods 
used and the quality of the technical platform, the microbiological results that we have reported appear anecdotal. In addition, the etiology and difficulties of diagnostis of Lower respiratory tract infection are very different from those of developed countries. In developed countries like the United States, in most cases, a microbiological etiological diagnosis is made, based on respiratory viral panel, or bacterial culture and often bronchoscopy [22]. The etiology of Lower respiratory infection is different in our study group due to a large number of unvaccinated children and a high prevalence of HIV. Therefore, for pneumonia, the isolation of the germ was effective in $79 \%$ of cases in the United States [4], against $1.2 \%$ in Thailand [3].

\subsection{Treatment}

In the absence of identification of the causative organisms, antibiotic treatment of ALRIs was probabilistic. It is known [16] [23] that bronchiolites are generally of viral origin, whether it is syncitial respiratory virus, adenoviruses, rhinoviruses, or human metapneumoviruses. Prescription from the outset of antibiotic therapy does not seem justified. But in children over 3 years old, Mycoplasma pneumoniae and Chlamydiae pneumoniae justify the use of macrolides. On the other hand, pneumonias are generally of bacterial origin and more than half of these are linked to pneumococcus when they pose a vital risk for infants and young children in developing countries [24]. Despite the appearance of Pneumococcus strains with reduced sensitivity to penicillin, we used mainly $\beta$-lactams, especially amoxicillin, and macrolides in case of atypical pneumonitis.

\subsection{Evolution}

The evolution of ALRI in children is generally favorable, with lethality varying between $0.9 \%$ and $6 \%$ [3] [4] [25]. In our department, it decreased: $16.3 \%$ in this work versus $20.4 \%$ in 2003 [6] but remains excessive. It appears necessary to put in place acute respiratory infection control programs in accordance with the WHO resolution [26] urging member states to undertake or intensify the fight against ALRIs to make them an essential element primary health care.

\section{Conclusion}

ALRIs are common in Brazzaville. Children under one year of age, who do not have complete immunization coverage, are the most affected. The most observed nosological varieties are bronchiolitis and pneumonia. Children under one year are the most affected. The determinants of death are, as elsewhere, denutrition, HIV seropositivity, poverty, inadequate immunization coverage.

\section{References}

[1] Marguet, C., Feray, D., Bocquel, N., et al. (2000) Les détresses respiratoires dans les services d'accueil et d'urgence pédiatriques: épidémiologie et critères d'évaluation. Archives de Pédiatrie, 7, 4-9. https://doi.org/10.1016/S0929-693X(00)88811-9 
[2] Lafaix, C.H. and Reinert, P.H. (1997) Morbidité et Mortalité de l'infection respiratoire aigüe chez l'enfant de moins de 5 ans dans le monde. Médecine et Maladies Infectieuses, 27, 507-512. https://doi.org/10.1016/S0399-077X(97)80105-9

[3] Sunakorn, P., Chunchit, L., Niltawat, S., Wangweerawong, M. and Jacobs, R.F. (1990) Epidemiology of Acute Respiratory Infection in Young Children from Thailand. The Pediatric Infectious Disease Journal, 9, 873-877. https://doi.org/10.1097/00006454-199012000-00003

[4] Forgie, IM., Campbell, H., Lloyd-Evans, N., et al. (1992) Etiology of Acute Lower Respiratory Tract Infections in Children in a Rural Community in the Gambia. The Pediatric Infectious Disease Journal, 11, 466-473. https://doi.org/10.1097/00006454-199206000-00009

[5] Ernest, S.K., Johnson, A.-W.E.R., Mokuolo, O.A., et al. (2014) Acute Respiratory Infections in the Middle-Belt Region of Nigeria. African Journal of Clinical and $E_{X-}$ perimental Microbiology, 15, 51-59.

[6] Mbika Cardorelle, A., Okoko, A.R. and Moyen, G. (2003) Infections respiratoires basses en réanimation pédiatrique à Brazzaville. Archives de Pédiatrie, 10, 548-549. https://doi.org/10.1016/S0929-693X(03)00173-8

[7] Bakonde, B., Tatagan, K., Kessie, K., et al. (1998) Epidémiologie hospitalière des infections respiratoires aigües basses chez le nourrisson et l'enfant togolais. Medecine d'Afrique Noire, 45, 435-439.

[8] Sawadogo, S., Sanou, I., Reinhardt, M., et al. (1997) La bronchiolite aigue du nourrisson en milieu hospitalier pédiatrique sahélien. Annales de Pediatrie, 44, 894-896.

[9] Ngombe, K., Mbombo-dinunga., Kabeya, N., et al. (2014) Infection respiratoire aigüe et statut nutritionnel chez les enfants de 0 à 5 ans: cas des cliniques universitaires de Lubumbashi, République Démocratique du Congo. Pan African Medical Journal, 19, 39.

[10] Adonis, L., Amon-Tanoh, F., Ngoan, A., et al. (1994) Profil général des affections respiratoires inferieures de l'enfant dans le service de pédiatrie du CHU de Yopougon. Medecine d'Afrique Noire, 129, 29-34.

[11] Berman, S. (1991) Epidemiology of Acute Respiratory Infections in Children of Developing Countries. Reviews of Infectious Diseases, 13, S454-S462.

[12] Esposito, P.M. (2013) Recurrent Lower Respiratory Tract Infections in Children: A Practical Approach to Diagnosis. Paediatric Respiratory Reviews, 14, 53-60.

[13] Oliveira, J., Bouzas, M., Cardoso, A., et al. (2016) Frequency of Complications and the Effects of Pneumococcal Vaccination in Young Children with Acute Respiratory Tract Infection. Vaccine, 34, 2256-2561.

[14] Vicente, D., Montes, M., Cilla, G., et al. (2003) Hospitalization for Respiratory Syncitial Virus in the Paediatric Population in Spain. Epidemiology \& Infection, 131, 867-872.

[15] Rigal, E., Maakaroun-vermesse, Z., Gaudy-Graffin, C., et al. (2010) Epidémiologie et description clinique des infections à métapneumovirus humain chez l'enfant. Archives De Pediatrie, 17, 26-33. https://doi.org/10.1016/j.arcped.2009.10.008

[16] Grimpel, E. (2001) Epidémiologie de la bronchiolite du nourrisson en France. Archives De Pediatrie, 8, 83-92. https://doi.org/10.1016/S0929-693X(01)80162-7

[17] Marcone, D.N., Alejandro, E., Videla, C., et al. (2013) Viral Etiology of Acute Respiratory Infections in Hospitalized and Outpatient Children in Buenos Aires, Argentina. The Pediatric Infectious Disease Journal, 3, 105-110. 
[18] Aubry, P. and Bernard-Alex, G. (2015) Infections Respiratoires Aigües. Med Trop, 1-3.

[19] Sanda, A. and Halidou, A. (1989) Etudes des pleurésies purulentes dans le service de pédiatrie B de l'hôpital national de Niamey. Medecine d Afrique Noire, 98, 56-59.

[20] Campbell, H., John, T.J., Simoes, Z., Steinhoff, M.C. and John, M. (1988) Evaluation of Simple Clinical Signs for the Diagnosis of Acute Lower Respiratory Tract Infection. The Lancet, 2, 125-128.

[21] Shann, F. (1995) The Management of Pneumonia in Children in Developing Countries. Clinical Infectious Diseases, 21, 218-225.

https://doi.org/10.1093/clind/21.Supplement_3.S218

[22] Espaillat, A., Mondal, P., Colon-Cortes, Y., Abu-Hasan, M. and Hegde, S. (2015) Pediatric Bronchoscopy in Children with Chronic Cough: Diagnostic and Therapeutic Yield. American Journal of Respiratory and Critical Care Medicine, 191, A3376-A3376.

[23] Ovetchkine, P. (2004) Antibiothérapie des infections respiratoires basses de l'enfant. Arch Ped, 11, 1277-1281. https://doi.org/10.1016/j.arcped.2004.05.003

[24] World Health Organization (1994) Division of Diarrhoeal and Acute Respiratory Disease, Ian, Control. Interim Report, WHO-CD4-95.1.

[25] Webb, C., Mwanajuma, N., Ngatia, A., et al. (2012) Treatment Failure among Kenyan Children with Severe Pneumonia-A Cohort Study. The Pediatric Infectious Disease Journal, 31, 152-157. https://doi.org/10.1097/INF.0b013e3182638012

[26] OMS (2007) Prévenir et combattre les maladies respiratoires aiguës à tendance épidémique ou pandémique dans le cadre des soins. WHO/CDS/EPR, Vol. 6, 18-29. 